Published in final edited form as:

Circulation. 2016 May 31; 133(22): 2159-2168. doi:10.1161/CIRCULATIONAHA.115.018175.

\title{
Regional Variation in Out-of-Hospital Cardiac Arrest Survival in the United States
}

Saket Girotra, MD, $\mathbf{S M}^{1}$, Sean van Diepen, MD, MSc $^{2}$, Brahmajee K. Nallamothu, MD, MPH ${ }^{3}$, Margaret Carrel, $\mathrm{PhD}^{4}$, Kimberly Vellano, $\mathrm{MPH}^{5}$, Monique L. Anderson, $\mathrm{MD}^{6}$, Bryan McNally, MD, MPH ${ }^{7}$, Benjamin Abella, MD, M.Phil ${ }^{8}$, Comilla Sasson, MD, PhD $^{9}$, Paul S. Chan, MD, MSc $^{10}$, and collaboration with CARES Surveillance Group and the HeartRescue Project ${ }^{1}$ Department of Internal Medicine, University of lowa Carver College of Medicine, lowa City, IA ${ }^{2}$ Division of Critical Care and Cardiology, University of Alberta, Edmonton, Alberta, Canada ${ }^{3}$ Center for Clinical Management Research, Ann Arbor VA Medical Center, \& Department of Internal Medicine, University of Michigan Medical School, Ann Arbor, MI

${ }^{4}$ Department of Geographic and Sustainability Sciences, University of lowa College of Liberal Arts and Sciences, lowa City, IA

${ }^{5}$ Department of Emergency Medicine, Emory University, Atlanta, GA

${ }^{6}$ Rollins School of Public Health, Atlanta, GA

${ }^{7}$ Department of Medicine, Duke Clinical Research Institute, Durham, NC

${ }^{8}$ Center for Resuscitation Science and Department of Emergency Medicine, University of Pennsylvania, Philadelphia, PA

${ }^{9}$ Department of Emergency Medicine, University of Colorado, Aurora, CO \& American Heart Association

${ }^{10}$ Saint Luke's Mid America Heart Institute and University of Missouri-Kansas, Kansas City, MO

\section{Abstract}

Background-Although previous studies have shown marked variation in out-of-hospital cardiac arrest survival across U.S. regions, factors underlying this survival variation remain incompletely explained.

Methods and Results-Using data from the Cardiac Arrest Registry to Enhance Survival, we identified 96,662 adult patients with out-of-hospital cardiac in 132 U.S. counties. We used hierarchical regression models to examine county-level variation in rates of survival and survival with functional recovery (defined as Cerebral Performance Category score of 1 or 2) and examined the contribution of demographics, cardiac arrest characteristics, bystander cardiopulmonary resuscitation (CPR), automated external defibrillator (AED) use, and county-level socio-

Correspondence: Saket Girotra MD, SM, Division of Cardiovascular Diseases, Department of Internal Medicine, University of Iowa Carver College of Medicine, 200 Hawkins Drive, Suite 4427 RCP, Iowa City, IA 52242, Phone: 319-384-7382, Fax: 319-356-4552, ; Email: saket-girotra@uiowa.edu

Disclosures: None. 
demographic factors in survival variation across counties. A total of 9317 (9.6\%) patients survived to discharge, and 7176 (7.4\%) achieved functional recovery. At a county-level, there was marked variation in rates of survival to discharge (range: 3.4\%-22.0\%, median odds ratio [MOR] 1.40, 95\% CI 1.32-1.46) and survival with functional recovery (range: $0.8 \%-21.0 \%$, MOR $1.53,95 \% \mathrm{CI}$ 1.43-1.62). County-level rates of bystander CPR and AED use were positively correlated with both outcomes $(\mathrm{P}<0.0001$ for all). Patient demographic and cardiac arrest characteristics explained $4.8 \%$ and $27.7 \%$ of the county-level variation in survival, respectively. Additional adjustment of bystander CPR and AED explained $41 \%$ of the survival variation, and this increased to $50.4 \%$ after adjustment of county-level socio-demographic factors. Similar findings were noted in analyses of survival with functional recovery.

Conclusions-Although out-of-hospital cardiac arrest survival varies significantly across U.S. counties, a substantial proportion of the variation is due to differences in bystander response across communities.

\section{Keywords}

cardiac arrest; cardiopulmonary resuscitation

\section{Introduction}

Out-of-hospital cardiac arrest accounts for nearly 300,000 deaths among adults each year in the U.S. ${ }^{1}$ Despite an overall high mortality associated with these events, survival rates have been reported to vary markedly based on geography. In the Resuscitation Outcomes Consortium (ROC) registry, which included data on out-of-hospital cardiac arrest from 7 participating U.S. and 3 Canadian sites, survival ranged by 5-fold - from 3.0\% in Alabama to $16.3 \%$ in Seattle, Washington. ${ }^{2}$ Findings from other regions of the country are unknown, as are reasons for such wide variation in survival. For example, regional variation in survival may be due, in part, to differences in patient case-mix, cardiac arrest characteristics (e.g., initial rhythm, location of arrest, etc.), and resuscitation treatment across sites-all of which are known to be key determinants for survival. ${ }^{3-6}$ It also remains unknown the extent to which this marked variation in survival is due to county-level differences in bystander delivery of cardiopulmonary resuscitation (CPR) or resources such as automated external defibrillators (AED). An understanding of the factors that underlie regional variation in outof-hospital cardiac arrest survival is critical for designing community-based, multi-faceted interventions for improving outcomes.

To address this gap in knowledge, we examined county-level variation in out-of-hospital cardiac arrest survival using data from the Cardiac Arrest Registry to Enhance Survival (CARES) - a large and geographically diverse database of out-of-hospital cardiac arrest patients in 31 states encompassing 80 million people in the U.S. We calculated the extent of variation in out-of-hospital cardiac arrest survival across U.S. counties using hierarchical regression models and quantified the relative contributions of patient factors, cardiac arrest characteristics, bystander response (CPR and AED use), and county-level sociodemographic factors in explaining any observed variation in survival. In addition, we also examined variation in survival with functional recovery- a key endpoint in the study of out- 
of-hospital cardiac arrest care that is infrequently reported but could vary in ways different from overall survival.

\section{Methods}

The CARES database was established in 2005 as a collaboration between Emory University School of Medicine and the Center for Disease Control and Prevention (CDC) for public health surveillance and continuous quality improvement for out-of-hospital cardiac arrest. Since inception, CARES has grown to involve over 800 emergency medical service (EMS) agencies across 405 counties in 31 states including 6 states with quality improvement efforts for cardiac arrest systems of care with the Heart Rescue initiative. ${ }^{7}$ Details of the study population, data collection, data reporting, and EMS and cardiac arrest protocols have been previously reported. ${ }^{8} 10$ The registry enrolls all 911 activated out-of-hospital-cardiac arrest events, defined as absence of pulse, apnea and unresponsiveness with attempted resuscitation by EMS or first responders and including those with termination of resuscitative efforts prior to hospital arrival. Patients are identified from data collected from the 911-dispatch centers, EMS agencies and receiving hospitals. Data collection within CARES is based on the Utstein-style definitions - a standardized template of uniform reporting guidelines for clinical variables and study outcomes that was developed by international resuscitation experts. ${ }^{11},{ }^{12}$ Until recently, only patients with a presumed cardiac etiology, defined as an arrest that is not known or likely to have been caused by trauma, submersion, drug overdose, asphyxia, exsanguination, or any other non-cardiac cause, as best determined by rescuers were included. However, due to the difficulty in ascertaining cardiac etiology by rescuers in the field, the inclusion criteria in CARES was modified in January 2013 to include all patients with non-traumatic out-of-hospital cardiac arrest. Study variables include patient demographics, cardiac arrest characteristics, address of the cardiac arrest location, EMS response, and in-hospital outcomes at participating sites.

Prior to enrollment, EMS and hospital users receive extensive training from a CARES program or a CARES state coordinator regarding data elements, data collection process, and the data management software. Data are entered using an online data-entry portal, or via direct upload from an agency's patient-care record. The data-entry portal also has built-in logic checks to minimize data-entry errors. A data analyst employed by CARES reviews all records for completeness and accuracy using an audit algorithm, and data-entry errors are flagged for further review. Moreover, each EMS agency is asked to confirm their nontraumatic call volume to ensure capture of all arrests in a geographic area. The volume of cardiac arrest during each month is compared with historical data for that EMS agency, and if a substantial change in monthly volume is noted, the EMS agency is notified. Finally, CARES also conducts a bi-annual assessment of each agency's case volume, and covered population, and link it to survival data and record volume to identify outliers across the registry. In the event of an outlier, CARES staff work closely with the agency to identify and resolve issues with data collection process. 


\section{Study Population}

Within CARES, we identified 147,415 patients 18 years of age or older with an out-ofhospital cardiac arrest of presumed cardiac etiology, between October 1, 2005 and December 31, 2014. We excluded 6,306 patients who had a do-not-resuscitate order. We also excluded cardiac arrests that were EMS-witnessed $(n=15,202)$ or occurred in a healthcare facility, hospital or nursing home $(n=21,416)$ due to a high likelihood of trained professionals involved in resuscitation in these situations. Since our planned analyses included evaluating the extent to which community level factors explained variation in survival, we also excluded cases for which the address at which the cardiac arrest occurred was either not available or could not be successfully geocoded ( $\mathrm{n}=887)$, as well as patients with missing data on survival $(\mathrm{n}=492)$. Finally, as our study sought to examine variation in survival at the county level (see below), we restricted our study population to only those counties with a cardiac arrest volume of at least 100 cases (6,450 cases from 273 counties excluded). Our final study population comprised 96,662 patients from 132 U.S. counties (Figure 1).

\section{Independent Variable and Study Outcomes}

The primary geographic unit of analysis was a U.S. county. Each patient within CARES was geocoded by the CDC to a U.S. latitude and longitude. Using these geocoded coordinates, each patient was then mapped to a U.S. county.

The primary outcome was survival to discharge, and the secondary outcome was survival with functional recovery. The latter was assessed using the previously described and validated cerebral performance category (CPC) score. ${ }^{13}$ A CPC score of 1 denotes mild or no neurologic disability, 2 moderate neurologic disability, 3 severe neurologic disability, 4 coma or vegetative state, and 5 brain death. We defined survival with functional recovery as survival to discharge with a CPC score of 1 or 2 .

\section{Study Variables}

Patient-level characteristics that were considered for risk-adjustment were age (categorized as 18-54, 55-64, 65-74, 775), sex, race (white, black, other or unknown), initial cardiac arrest rhythm (categorized as non-shockable [asystole, pulseless electrical activity, unknown non-shockable rhythm] and shockable [ventricular fibrillation, ventricular tachycardia, unknown shockable rhythm]), location of arrest (home or public area), whether cardiac arrest was witnessed by a bystander (i.e., someone other than a first responder [fire department or police personnel] or the EMS provider), initiation of CPR by a bystander, and bystander use of an AED. Given that out-of-hospital cardiac arrest survival in CARES has improved over time, ${ }^{14}$ and that different EMS agencies joined CARES at different timepoints, we also included calendar year as a variable in our models to ensure that survival variation between counties was not confounded by temporal trends in out-of-hospital cardiac arrest survival.

In order to characterize county-level effects in our analyses, we obtained data on the following variables at the county-level from the American Community Survey 2008-2012: median age, proportion of black and male residents in each county, average family size, 
median household income, and population density per-square mile. ${ }^{15}$ For each county, we also calculated rates of bystander CPR and bystander AED use within CARES as follows. Rates of bystander CPR were calculated by dividing the number of cardiac arrest victims who received bystander CPR by the total number of cardiac arrests in each county. Similarly, we calculated rates of bystander AED use for each county by dividing the total number of cardiac arrest victims who were assessed with an AED prior to the arrival of EMS personnel by the total number of cardiac arrests in each county.

\section{Statistical Analysis}

Since the primary geographic unit of analysis was the county, we first calculated the unadjusted survival rate for out-of-hospital cardiac arrest within each county and descriptively examined variation in survival rates using graphical methods. We then ranked and grouped counties into quartiles according to their unadjusted survival rates and evaluated differences in demographics, cardiac arrest characteristics, bystander response (CPR and AED), and county-level socio-demographic characteristics using the Cochran Armitage test of trend for categorical variables and linear regression for continuous variables. We also examined the Pearson's correlation between unadjusted county-level rates of survival and county-level rates of bystander CPR and AED use.

Two-level multivariable hierarchical models (with patients nested within counties) were used to assess the relationship between the aforementioned patient-level and county-level factors and survival outcomes. ${ }^{16}$ Hierarchical models account for clustering of patients within each county and avoid over-estimation of the significance of statistical associations. They also allow an estimation of the independent contribution of patient-level and county-level factors in explaining the survival variation across counties.

In these models, we first quantified the extent of variation in survival between counties by calculating the unadjusted median odds ratio (OR). ${ }^{17}$ The median OR is derived from the variance estimate of the random intercept from the hierarchical model, and is always greater than 1. Conceptually, the median OR represents the relative odds of survival for two identical patients (i.e., similar patient, cardiac arrest, and county characteristics) with an outof-hospital cardiac arrest in one randomly selected county compared with another randomly selected county. A median OR of 1.0 indicates no county-level variation in survival, whereas a median OR of 1.50 indicates that the odds of survival for a patient are $50 \%$ higher in one randomly selected county compared with another randomly selected county.

We then determined the extent to which variation in survival across counties (as measured by the unadjusted median OR) was explained by patient factors, cardiac arrest characteristics, bystander response (CPR and AED use), and county-level sociodemographic factors. To accomplish this, we constructed a sequence of hierarchical models which cumulatively adjusted for the following groups of variables: 1) patient demographic factors (age, sex, race), 2) cardiac arrest characteristics (initial rhythm, location of arrest, witnessed arrest, and calendar year) 3) bystander CPR and AED use, and rates of bystander CPR and AED at a county-level, and 4) county-level socio-demographic characteristics (median age, racial and gender composition, median household income, family size, and population density in 2010). In these models, each county was modeled as a random effect 
whereas patient-level and county-level variables were modeled as fixed effects. We calculated the median OR at each step and compared it with the median OR from the unadjusted model. We also determined the extent of variation accounted by each sequence of adjustment by determining the degree to which the variance for the county-level random effect was attenuated with the addition of variables at each step. Finally, we quantified the independent association between county-level rates of bystander CPR and AED with survival using hierarchical models similar to those described above with the exception that county-level demographic variables that were at least moderately correlated with bystander CPR and AED use (absolute Pearson's correlation coefficient > 0.40) were not included (Supplemental Table 1). This was done to avoid over-adjusting the effect of bystander CPR and AED on survival, as a recent study showed a strong association between bystander CPR and neighborhood characteristics. ${ }^{18}$ Moreover, unlike most county-level socio-demographic characteristics, which are not modifiable, bystander CPR and AED rates are potentially amenable to intervention. All aforementioned analyses were repeated for the outcome of survival with functional recovery.

\section{Sensitivity Analyses}

We conducted additional analyses to determine the robustness of our study findings. First, in light of evidence from a recent study that suggested significant differences in post-discharge survival in patients with CPC of 1 vs. CPC of $2,{ }^{19}$ we explored whether the extent of countylevel variation in survival with functional recovery was sensitive to the CPC cut-off used in this study (CPC of 1 or 2 vs. CPC of 1). Second, since data on hypothermia or coronary angiography was not collected in CARES registry until 2010, we were unable to examine their contribution on survival variation in our main analyses. However, we addressed this limitation by restricting our cohort to 2010-2014 and repeated the analyses above to determine relative impact of hypothermia and early coronary angiography in explaining survival variation across counties. The detailed methodology is described in the Supplemental Methods.

Overall, data were missing in $<1 \%$ of patients except race. Due to its sensitive nature, race was not consistently reported by EMS agencies and was missing in $26.4 \%$ of patients. For these patients, race was coded as "unknown" and evaluated as a separate dummy variable in our models.

All statistical analyses were performed using SAS 9.3 (version 9.3 Cary, NC: SAS Institute. 2002-2010). We used the PROC GLIMMIX feature in SAS to construct the hierarchical regression models described above. Geocoding was performed using Centrus Desktop geocoder, version 6.00.01.N (Physio-Control Data Solutions, Duluth, Minnesota). The institutional review board at University of Iowa approved the study protocol and waived the requirement for informed consent as the study only included de-identified data.

\section{Results}

A total of 96,662 patients with out-of-hospital cardiac arrest from 132 U.S. counties were included in this study. The list of 31 states and the number of counties per state are summarized in Supplemental Table 2. Nearly 1 in 4 (24.9\%) patients had an initial shockable 
rhythm. The mean age was 63.7 years, and $36.4 \%$ were women. Fewer than half (43.9\%) had a witnessed arrest, $34.4 \%$ received bystander CPR, and $2.3 \%$ were assessed with an AED (Table 1). Overall, a total of 9317 (9.6\%) patients survived to discharge, and 7176 $(7.4 \%)$ achieved functional recovery at discharge (Table 1$)$.

Compared to study patients, patients who were excluded due to low county case-volume were more likely to be men, belong to white race, and have a witnessed arrest, an initial shockable rhythm, and receive bystander CPR (Supplemental Table 3). Nearly all (97\%) of the excluded patients were enrolled during 2011-2014. Unadjusted survival was similar in both groups $(9.6 \%$ vs. $9.2 \%, \mathrm{P}=0.21)$, but survival with functional recovery was higher in excluded patients ( $7.4 \%$ vs. $8.1 \%, \mathrm{P}=0.042)$.

There was marked county-level variation in overall rates of survival to discharge, and survival with functional recovery (Figures $2 \mathrm{~A} \& 2 \mathrm{~B}$ ). Rates of survival to discharge ranged from $3.4 \%$ to $22.0 \%$, while rates of survival with functional recovery ranged from $0.8 \%$ to $20.1 \%$. We categorized counties into quartiles based on their unadjusted survival (Quartile 1: $<7.7 \%$, Quartile 2: $7.7 \%$ to $9.6 \%$, Quartile 3: $9.7 \%$ to $12.1 \%$, Quartile $4:>12.1 \%$ ). There were significant differences in a number of patient characteristics between quartiles (Table 1). Cardiac arrest patients in counties in the lowest quartile were older, more likely to be female, and were less likely to have a witnessed arrest, receive bystander CPR, be assessed with an AED prior to EMS arrival, and have an initial shockable rhythm ( $\mathrm{P}$ for trend $<0.0001$ for all, Table 1). At a county-level, there were significant differences with regards to racial composition of residents. Nearly $21 \%$ of residents in counties in the lowest quartile of survival (quartile 1) were black compared to $11.6 \%$ in the $2^{\text {nd }}$ quartile, $8.5 \%$ in the $3^{\text {rd }}$ quartile, and $6.2 \%$ in the highest survival quartile (quartile 4 , P for trend $<0.0001$, Table 2).

There was a significant positive correlation between county-level rates of bystander CPR with rates of survival to discharge $(\rho=0.42, \mathrm{P}<0.0001)$ and survival with functional recovery $(\rho=0.43, \mathrm{P}<0.0001$, Figure 3A). Likewise, county-level rates of bystander AED use were also strongly correlated with rates of survival to discharge $(\rho=0.40, P<0.0001)$ and survival with functional recovery $(\rho=0.44, \mathrm{P}<0.0001$, Figure $3 \mathrm{~B})$.

For the outcome of survival to discharge, the unadjusted median odds ratio was 1.40 (95\% CI 1.32-1.46), which suggests that there is a median $40 \%$ difference in odds of survival for random subjects with out-of-hospital cardiac arrest in two randomly selected counties. Sequential adjustment for patient demographics, and cardiac arrest characteristics explained $4.8 \%$ and $27.7 \%$ of the county-level variation in survival, respectively (Table 3). Additional adjustment for bystander response explained a total of $41.0 \%$ of the county-level variation in survival, and this proportion increased to $50.4 \%$ after adjusting for other county-level characteristics. The final model for patient and county-level characteristics is described in Supplemental Table 4. At a county-level, rates of bystander CPR, median age and median household income were significantly associated with overall survival, whereas rates of bystander AED use were not.

The unadjusted median odds ratio for survival with functional recovery was 1.53 (95\% CI 1.43-1.62). Sequential adjustment of demographic and cardiac arrest variables explained 
$10.9 \%$ and $27.7 \%$ of county-level variation in survival with functional recovery, respectively. The proportion of county-level variation explained increased to $37.2 \%$ after adjustment of bystander response, and $49.9 \%$ after adjustment for other county-level characteristics (Table 3). At a county-level, rates of bystander CPR, median age, and median household income were associated with survival with functional recovery (Supplemental Table 4). The above results were qualitatively similar when we used a CPC of 1 to define survival with functional recovery (Supplemental Table 5).

In sensitivity analyses, we also determined the impact of hypothermia and coronary angiography in explaining survival variation across counties with available data on these variables. The median rate of hypothermia in eligible patients was $54.1 \%$ (IQR: 46.4\%-66.0\%; $\mathrm{n}=109$ counties, 64,871 patients), and the median rate of early coronary angiography was $45.4 \%$ (IQR: $33.3 \%-55.2 \%$; $\mathrm{n}=59$ counties, 18,677 patients). Results of the hierarchical models within this subgroup are summarized in Supplemental Tables 6 and 7. We found that sequential adjustment of hypothermia use explained $1.8 \%$ of variation in survival to discharge (median OR decreased from 1.27 to 1.26), and 3.8\% of variation in survival with functional recovery (median OR went from 1.30 to 1.29 ) across counties. Sequential adjustment of coronary angiography explained $8 \%$ of variation in survival to discharge (median OR decreased from 1.25 to 1.23 ) and $8 \%$ of variation in survival with functional recovery (median OR decreased from 1.31 to 1.29).

\section{Discussion}

In this large out-of-hospital cardiac arrest registry, we found marked variation in rates of survival to discharge and functional recovery across U.S. counties. The relative odds of survival to discharge varied by nearly $40 \%$ between counties, while the relative odds of survival with functional recovery varied by $53 \%$. Although a large proportion of countylevel variation in survival remained unexplained, a substantial proportion of the explained variation was due to differences in patient demographics, cardiac arrest characteristics, bystander response and socio-demographic characteristics of communities. Notably, bystander CPR was the factor most amenable to modification. Collectively, our findings highlight large variations in survival outcomes for out-of-hospital cardiac arrest and suggest that public health interventions, such as those that improve rates of bystander CPR, have the potential to improve low survival rates for this condition, especially in low-performing counties which we found had a disproportionately higher proportion of black residents.

Regional variation in out-of-hospital cardiac arrest survival has been previously described in the ROC registry, which reported that rates of survival ranged more than 5-fold, from 3.0\% in Alabama to $16.3 \%$ in Seattle, after adjustment for age and sex. ${ }^{2}$ In another study from the ROC registry, Rea et al found that adjustment of demographics, cardiac arrest characteristics, and bystander response explained about $43 \%$ of survival variation across sites in the ROC registry. ${ }^{20}$ However, that study only included 7 North American regions, thereby limiting generalizability. Moreover, survival with functional recovery - a key endpoint in out-of-hospital cardiac arrest was not available. Our study extends the work of the ROC investigators by examining variation in cardiac arrest survival in a larger and more geographically diverse group of U.S. communities. We were able to quantify the extent of 
variation in rates of survival to discharge and functional recovery across 132 U.S. counties and determine the relative contribution of demographic factors, cardiac arrest characteristics, bystander response and county-level characteristics, using sequential hierarchical regression models. Importantly, county-level rates of bystander CPR were not only associated with survival to discharge and functional recovery, but also accounted for a sizeable proportion of the site-level variation in both outcomes, highlighting the importance of this critical intervention.

A recent study showed marked variation in rates of bystander CPR across neighborhoods in the United States. ${ }^{18}$ Odds of receiving bystander CPR for a cardiac arrest victim were 51\% lower if the arrest occurred in a low-income black neighborhood compared to a high-income white neighborhood. In this study, we extend this prior work by showing that communities with low rates of bystander CPR also had lower rates of out-of-hospital cardiac arrest survival. Given the over-representation of black residents in communities with poor survival rates, our findings suggest that a renewed emphasis by national organizations on improving rates of bystander CPR in communities with low rates of bystander CPR may not only improve survival outcomes overall, but could also be a potential strategy to reduce existing racial disparities in out-of-hospital cardiac arrest survival. ${ }^{18,21}$

A broad-based national strategy for improving rates of bystander CPR has previously been found to be successful in Denmark. This national program included 1) mandatory CPR training in elementary schools, as well as at the time of acquiring a driver's license, 2) country-wide dissemination of free CPR education kits, and 3) improvement in dispatchassisted bystander CPR. As a result of these efforts, there was a greater than 2-fold increase within a 10-year period in the provision of bystander CPR for out-of-hospital cardiac arrest in Denmark (from $21.1 \%$ in 2001 to $44.9 \%$ in 2010), which was accompanied by a significant increase in survival (1-year survival increased from $2.9 \%$ in 2001 to $10.2 \%$ in $2010){ }^{22}$ More recently, a randomized trial found that use of mobile technology to recruit trained volunteers has the potential to increase rates of bystander CPR. ${ }^{23}$ Both of these studies demonstrated that bystander CPR rates are modifiable but require carefully designed interventions.

Low rates of bystander CPR in the United States may be due to a number of factors. Surveys have shown that bystanders may be reluctant to perform CPR for concerns about transmission of infectious diseases, legal liability, or 'fear of failure'. ${ }^{21}$ Moreover, until recently, the complexity of the CPR guidelines was an impediment to the learning, retention and delivery of CPR. However, findings from recent studies, which suggest that outcomes with compression-only CPR may be similar to conventional CPR with regards to survival, are encouraging. ${ }^{24}$ Importantly, compression-only CPR is simpler to perform and retain, minimizes interruptions and avoids mouth-to-mouth ventilation, and therefore is more likely to be adopted by community members. Future studies are needed to determine whether specific community-based interventions, which promote the adoption of compression-only CPR, result in an improvement in overall survival, especially in communities with poor survival rates. 
Although bystander use of AED was strongly associated with survival at a patient-level, county-level differences in bystander AED use did not explain the survival variation across counties in adjusted analyses. This is likely because overall rate of bystander AED use was low (mean: $2.1 \%$, range: $0.0 \%-7.0 \%$ ) suggesting that these analyses may have been underpowered. However, previous studies that have suggested a benefit of AED on survival were limited to cardiac arrests in a public location (e.g., shopping malls, casinos). ${ }^{25.27}$ To date, home use of AEDs has not been shown to significantly improve survival from sudden cardiac arrest in patients at risk for such events. ${ }^{28}$ Given that a majority of out-of-hospital cardiac arrests occur in a home location ( $~ 82 \%$ in our study), our finding of a lack of association between bystander AED use at a county-level and survival is not altogether surprising.

Our study findings should be interpreted in light of the following limitations. First, although we evaluated a number of county-level characteristics, our analysis lacked information on some key variables (e.g., EMS response times and time to return of spontaneous circulation). Nonetheless, these factors reflect county-level variations in response times and resuscitation care and are likely mediators of the observed variation that exists. Second, information on some important patient and treatment variables (e.g., co-morbidities, quality of CPR, frequency of interruptions, etc.), which are important determinants of survival, were also not available within CARES and may lead to unmeasured confounding for the calculation of the median ORs across counties and/or account for some of the unmeasured variation in survival outcomes. Although race was available, it was missing in nearly $26 \%$ of patients. Moreover, information on race was obtained using a combination of patient/family self-report and EMS provider assessment, and the accuracy of the above approach is unknown. Third, information regarding hospital treatments (e.g., use of hypothermia, coronary angiography) was not consistently collected during the study period. However, in a subgroup analysis, we found that variation in use of hypothermia only accounted for a small proportion of county-level variation in overall survival. Although the relative impact of coronary angiography on county-level variation in survival outcomes was greater, these findings need to be confirmed in other cohorts where data collection on the above variables is more consistent. Fourth, counties are heterogeneous in terms of socio-demographic characteristics of residents, and resources, and our choice of county as the unit of analysis may have underestimated the association between community-level characteristics and survival outcome. Nonetheless, EMS response in many states is organized at a county-level, thus making our use of counties as the unit of measurement more interpretable. ${ }^{29}$ Fifth, assessment of survival with functional recovery using CPC scores at discharge may be confounded by variation in hospital discharge practices. Lastly, although CARES is the largest database of out-ofhospital cardiac arrest in the United States with a large catchment area, our study only included a total of 132 U.S. counties. Therefore, our results may not be generalizable to other U.S. counties especially low-volume counties that were excluded from this study.

In conclusion, we found substantial variation across U.S. counties in survival and survival with functional recovery following out-of-hospital cardiac arrest, which was partly explained by regional differences in patient demographics, cardiac arrest characteristics, use of bystander CPR, and community-level socio-demographic characteristics. County-level rates of bystander CPR accounted for a substantial proportion of the explained variation in these 
cardiac arrest outcomes. Our findings suggest that focused public health interventions to improve rates of bystander CPR could potentially improve survival outcomes for out-ofhospital cardiac arrest, especially in communities with poor survival.

\section{Supplementary Material}

Refer to Web version on PubMed Central for supplementary material.

\section{Acknowledgments}

Authorship: Dr. Girotra had full access to all of the data in the study, and takes responsibility for the integrity of the data and the accuracy of the data analysis. Study Concept and design: Girotra, Chan. Acquisition of Data: Girotra, Carrel, Vellano, McNally. Statistical Analysis: Girotra. Analysis and interpretation of data: Girotra, van Diepen, Nallamothu, Carrel, Vellano, Anderson, McNally, Abella, Sasson, Chan. Drafting of the manuscript: Girotra. Critical revision of the manuscript for important intellectual content: Girotra, van Diepen, Nallamothu, Carrel, Vellano, Anderson, McNally, Abella, Sasson, Chan. Study Supervision: Girotra.

Funding Sources Drs. Girotra (K08HL122527), Nallamothu (R01HL123980), and Chan (K23HL102224, R01HL123980) are funded by the National Heart Lung and Blood Institute. CARES was funded by the Centers for Disease Control and Prevention (CDC) from 2004-2012. The program is now supported through private funding from the American Red Cross, the Medtronic Foundation Heart Rescue Program, the American Heart Association, Zoll Corporation, and in-kind support from Emory University. At present, the CDC provides technical assistance for the CARES program but does not provide any funding.

\section{References}

1. Go AS, Mozaffarian D, Roger VL, Benjamin EJ, Berry JD, Blaha MJ, Dai S, Ford ES, Fox CS, Franco S, Fullerton HJ, Gillespie C, Hailpern SM, Heit JA, Howard VJ, Huffman MD, Judd SE, Kissela BM, Kittner SJ, Lackland DT, Lichtman JH, Lisabeth LD, Mackey RH, Magid DJ, Marcus GM, Marelli A, Matchar DB, McGuire DK, Mohler ER 3rd, Moy CS, Mussolino ME, Neumar RW, Nichol G, Pandey DK, Paynter NP, Reeves MJ, Sorlie PD, Stein J, Towfighi A, Turan TN, Virani SS, Wong ND, Woo D, Turner MB. Heart disease and stroke statistics--2014 update: A report from the american heart association. Circulation. 2014; 129:e28-e292. [PubMed: 24352519]

2. Nichol G, Thomas E, Callaway CW, Hedges J, Powell JL, Aufderheide TP, Rea T, Lowe R, Brown T, Dreyer J, Davis D, Idris A, Stiell I. Resuscitation Outcomes Consortium I. Regional variation in out-of-hospital cardiac arrest incidence and outcome. JAMA. 2008; 300:1423-1431. [PubMed: 18812533]

3. Sasson C, Rogers MA, Dahl J, Kellermann AL. Predictors of survival from out-of-hospital cardiac arrest: A systematic review and meta-analysis. Circ Cardiovasc Qual Outcomes. 2010; 3:63-81. [PubMed: 20123673]

4. Herlitz J, Engdahl J, Svensson L, Angquist KA, Young M, Holmberg S. Factors associated with an increased chance of survival among patients suffering from an out-of-hospital cardiac arrest in a national perspective in sweden. AmHeart J. 2005; 149:61-66.

5. Herlitz J, Engdahl J, Svensson L, Young M, Angquist KA, Holmberg S. A short delay from out of hospital cardiac arrest to call for ambulance increases survival. Eur Heart J. 2003; 24:1750-1755. [PubMed: 14522570]

6. van de Glind EM, van Munster BC, van de Wetering FT, van Delden JJ, Scholten RJ, Hooft L. Prearrest predictors of survival after resuscitation from out-of-hospital cardiac arrest in the elderly a systematic review. BMC Geriatr. 2013; 13:68. [PubMed: 23819760]

7. van Diepen S, Abella BS, Bobrow BJ, Nichol G, Jollis JG, Mellor J, Racht EM, Yannopoulos D, Granger CB, Sayre MR. Multistate implementation of guideline-based cardiac resuscitation systems of care: Description of the heartrescue project. Am Heart J. 2013; 166:647-653. e642. [PubMed: 24093843]

8. McNally B, Robb R, Mehta M, Vellano K, Valderrama AL, Yoon PW, Sasson C, Crouch A, Perez AB, Merritt R, Kellermann A. Centers for Disease C, Prevention. Out-of-hospital cardiac arrest 
surveillance --- cardiac arrest registry to enhance survival (cares), united states, october 1, 2005-december 31, 2010. MMWR Surveill Summ. 2011; 60:1-19. [PubMed: 21796098]

9. McNally B, Stokes A, Crouch A, Kellermann AL. Group CS. Cares: Cardiac arrest registry to enhance survival. Ann Emerg Med. 2009; 54:674-683. e672. [PubMed: 19394110]

10. Abrams HC, McNally B, Ong M, Moyer PH, Dyer KS. A composite model of survival from outof-hospital cardiac arrest using the cardiac arrest registry to enhance survival (cares). Resuscitation. 2013; 84:1093-1098. [PubMed: 23603289]

11. Cummins RO, Chamberlain DA, Abramson NS, Allen M, Baskett PJ, Becker L, Bossaert L, Delooz HH, Dick WF, Eisenberg MS, et al. Recommended guidelines for uniform reporting of data from out-of-hospital cardiac arrest: The utstein style. A statement for health professionals from a task force of the american heart association, the european resuscitation council, the heart and stroke foundation of canada, and the australian resuscitation council. Circulation. 1991; 84:960-975. [PubMed: 1860248]

12. Jacobs I, Nadkarni V, Bahr J, Berg RA, Billi JE, Bossaert L, Cassan P, Coovadia A, D’Este K, Finn J, Halperin H, Handley A, Herlitz J, Hickey R, Idris A, Kloeck W, Larkin GL, Mancini ME, Mason P, Mears G, Monsieurs K, Montgomery W, Morley P, Nichol G, Nolan J, Okada K, Perlman J, Shuster M, Steen PA, Sterz F, Tibballs J, Timerman S, Truitt T, Zideman D. Cardiac arrest and cardiopulmonary resuscitation outcome reports: Update and simplification of the utstein templates for resuscitation registries: A statement for healthcare professionals from a task force of the international liaison committee on resuscitation (american heart association, european resuscitation council, australian resuscitation council, new zealand resuscitation council, heart and stroke foundation of canada, interamerican heart foundation, resuscitation councils of southern africa). Circulation. 2004; 110:3385-3397. [PubMed: 15557386]

13. Jennett B, Bond M. Assessment of outcome after severe brain damage. Lancet. 1975; 1:480-484. [PubMed: 46957]

14. Chan PS, McNally B, Tang F, Kellermann A. Group CS. Recent trends in survival from out-ofhospital cardiac arrest in the united states. Circulation. 2014; 130:1876-1882. [PubMed: 25399396]

15. [june 1, 2015] http://www.Census.Gov/acs/www/

16. Goldstein H, Browne W, Rasbash J. Multilevel modelling of medical data. Stat Med. 2002; 21:3291-3315. [PubMed: 12375305]

17. Larsen K, Merlo J. Appropriate assessment of neighborhood effects on individual health: Integrating random and fixed effects in multilevel logistic regression. Am J Epidemiol. 2005; 161:81-88. [PubMed: 15615918]

18. Sasson C, Magid DJ, Chan P, Root ED, McNally BF, Kellermann AL, Haukoos JS, Group CS. Association of neighborhood characteristics with bystander-initiated cpr. N Engl J Med. 2012; 367:1607-1615. [PubMed: 23094722]

19. Chan PS, Nallamothu BK, Krumholz HM, Spertus JA, Li Y, Hammill BG, Curtis LH. American Heart Association Get with the Guidelines-Resuscitation I. Long-term outcomes in elderly survivors of in-hospital cardiac arrest. N Engl J Med. 2013; 368:1019-1026. [PubMed: 23484828]

20. Rea TD, Cook AJ, Stiell IG, Powell J, Bigham B, Callaway CW, Chugh S, Aufderheide TP, Morrison L, Terndrup TE, Beaudoin T, Wittwer L, Davis D, Idris A, Nichol G. Resuscitation Outcomes Consortium I. Predicting survival after out-of-hospital cardiac arrest: Role of the utstein data elements. Ann Emerg Med. 2010:55, 249-257.

21. Abella BS, Aufderheide TP, Eigel B, Hickey RW, Longstreth WT Jr, Nadkarni V, Nichol G, Sayre MR, Sommargren CE, Hazinski MF. American Heart A. Reducing barriers for implementation of bystander-initiated cardiopulmonary resuscitation: A scientific statement from the american heart association for healthcare providers, policymakers, and community leaders regarding the effectiveness of cardiopulmonary resuscitation. Circulation. 2008; 117:704-709. [PubMed: 18195177]

22. Wissenberg M, Lippert FK, Folke F, Weeke P, Hansen CM, Christensen EF, Jans H, Hansen PA, Lang-Jensen T, Olesen JB, Lindhardsen J, Fosbol EL, Nielsen SL, Gislason GH, Kober L, TorpPedersen C. Association of national initiatives to improve cardiac arrest management with rates of bystander intervention and patient survival after out-of-hospital cardiac arrest. JAMA. 2013; 310:1377-1384. [PubMed: 24084923] 
23. Ringh M, Rosenqvist M, Hollenberg J, Jonsson M, Fredman D, Nordberg P, Jarnbert-Pettersson H, Hasselqvist-Ax I, Riva G, Svensson L. Mobile-phone dispatch of laypersons for cpr in out-ofhospital cardiac arrest. N Engl J Med. 2015; 372:2316-2325. [PubMed: 26061836]

24. Rea TD, Fahrenbruch C, Culley L, Donohoe RT, Hambly C, Innes J, Bloomingdale M, Subido C, Romines S, Eisenberg MS. Cpr with chest compression alone or with rescue breathing. N Engl J Med. 2010; 363:423-433. [PubMed: 20818863]

25. Hallstrom AP, Ornato JP, Weisfeldt M, Travers A, Christenson J, McBurnie MA, Zalenski R, Becker LB, Schron EB, Proschan M. Public Access Defibrillation Trial I. Public-access defibrillation and survival after out-of-hospital cardiac arrest. N Engl J Med. 2004; 351:637-646. [PubMed: 15306665]

26. Caffrey SL, Willoughby PJ, Pepe PE, Becker LB. Public use of automated external defibrillators. N Engl J Med. 2002; 347:1242-1247. [PubMed: 12393821]

27. Valenzuela TD, Roe DJ, Nichol G, Clark LL, Spaite DW, Hardman RG. Outcomes of rapid defibrillation by security officers after cardiac arrest in casinos. N Engl J Med. 2000; 343:12061209. [PubMed: 11071670]

28. Bardy GH, Lee KL, Mark DB, Poole JE, Toff WD, Tonkin AM, Smith W, Dorian P, Packer DL, White RD, Longstreth WT Jr, Anderson J, Johnson G, Bischoff E, Yallop JJ, McNulty S, Ray LD. Clapp-Channing NE, Rosenberg Y, Schron EB, Investigators HAT. Home use of automated external defibrillators for sudden cardiac arrest. N Engl J Med. 2008; 358:1793-1804. [PubMed: 18381485]

29. [June 10, 2015] http://www.Emsmuseum.Org/virtual-museum/history/articles/403116-emergencymedical-services-in-the-united-states-of-america-in-1995 


\section{Clinical Perspectives}

Out-of-hospital cardiac arrest is common, and associated with poor survival and neurological outcomes. Although previous studies have documented marked variation in out-of-hospital cardiac arrest survival based on geography, few studies have examined factors that explain survival variation across communities. Using data from a large registry of out-of-hospital cardiac arrests in the United States, we found a marked variation in rates of survival to discharge (range: $3.4 \%-22.0 \%$, median odds ratio 1.40 ), and survival with functional recovery (range: $0.7 \%-16.2 \%$, median odds ratio 1.60 ) across U.S. counties. County-level rates of bystander CPR and bystander AED use were positively correlated with both outcomes $(\mathrm{P}<0.0001$ for all). Patient demographic and cardiac arrest characteristics explained $4.8 \%$ and $27.7 \%$ of the county-level variation in survival, respectively. Additional adjustment of bystander response explained $41 \%$ of the survival variation, and this increased to $50.4 \%$ after adjustment of county-level sociodemographic factors. Similar findings were noted in analyses of survival with functional recovery. Importantly, a substantial proportion of explained variation in survival across communities was due to variation in rates of bystander CPR - a factor that is most amenable to intervention. Collectively, our findings highlight large variation in survival outcomes for out-of-hospital cardiac arrest and suggest that public health interventions, such as those that improve rates of bystander CPR, have the potential to improve low survival rates for this condition. 
141,109 adults ( 421 counties) with out-ofhospital cardiac arrest due to presumed cardiac etiology with resuscitation attempted in the field

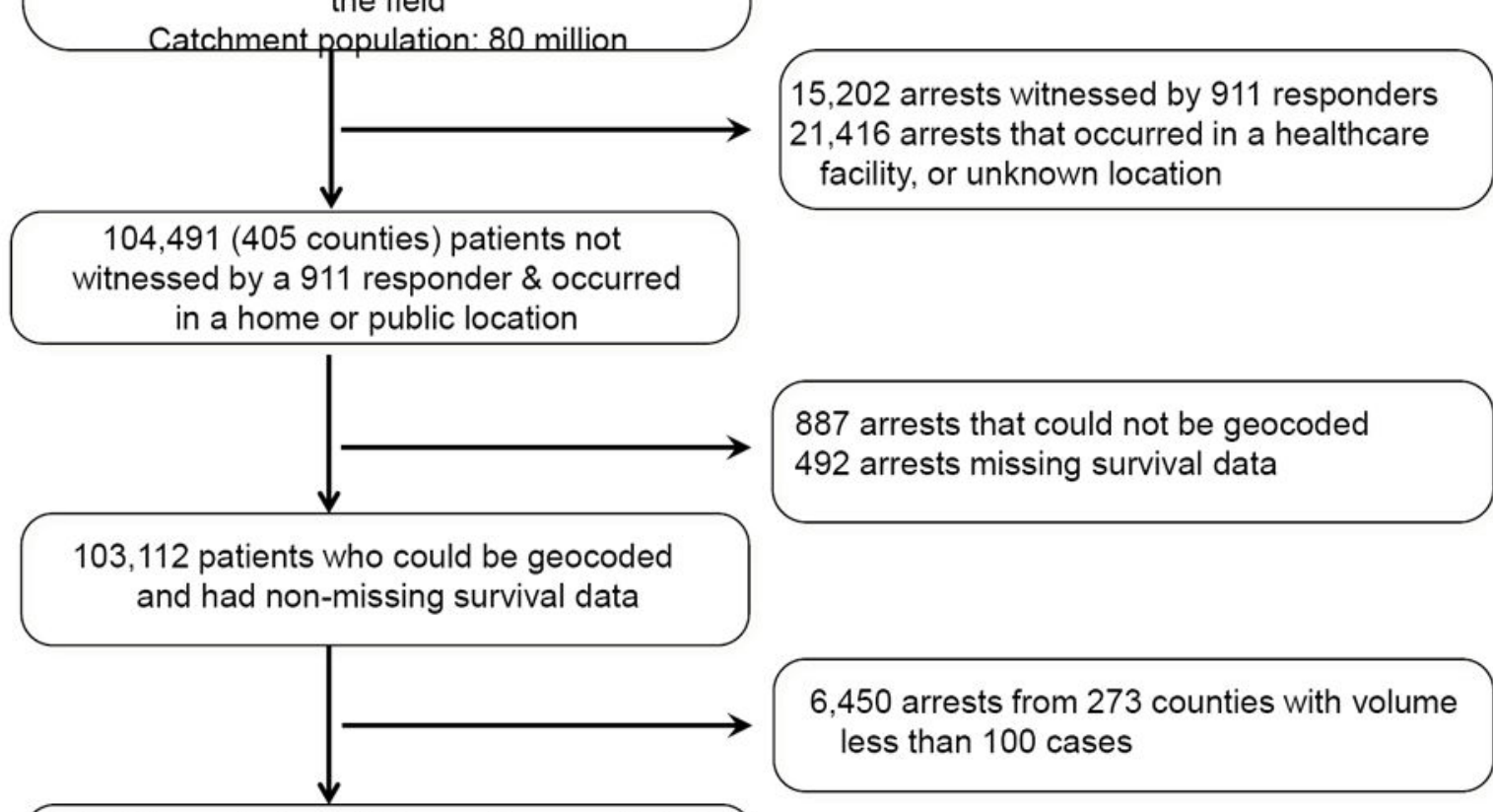

96,662 arrests from 132 counties constituted the final study population Catchment population: 56.3 million

Figure 1.

Study Cohort 


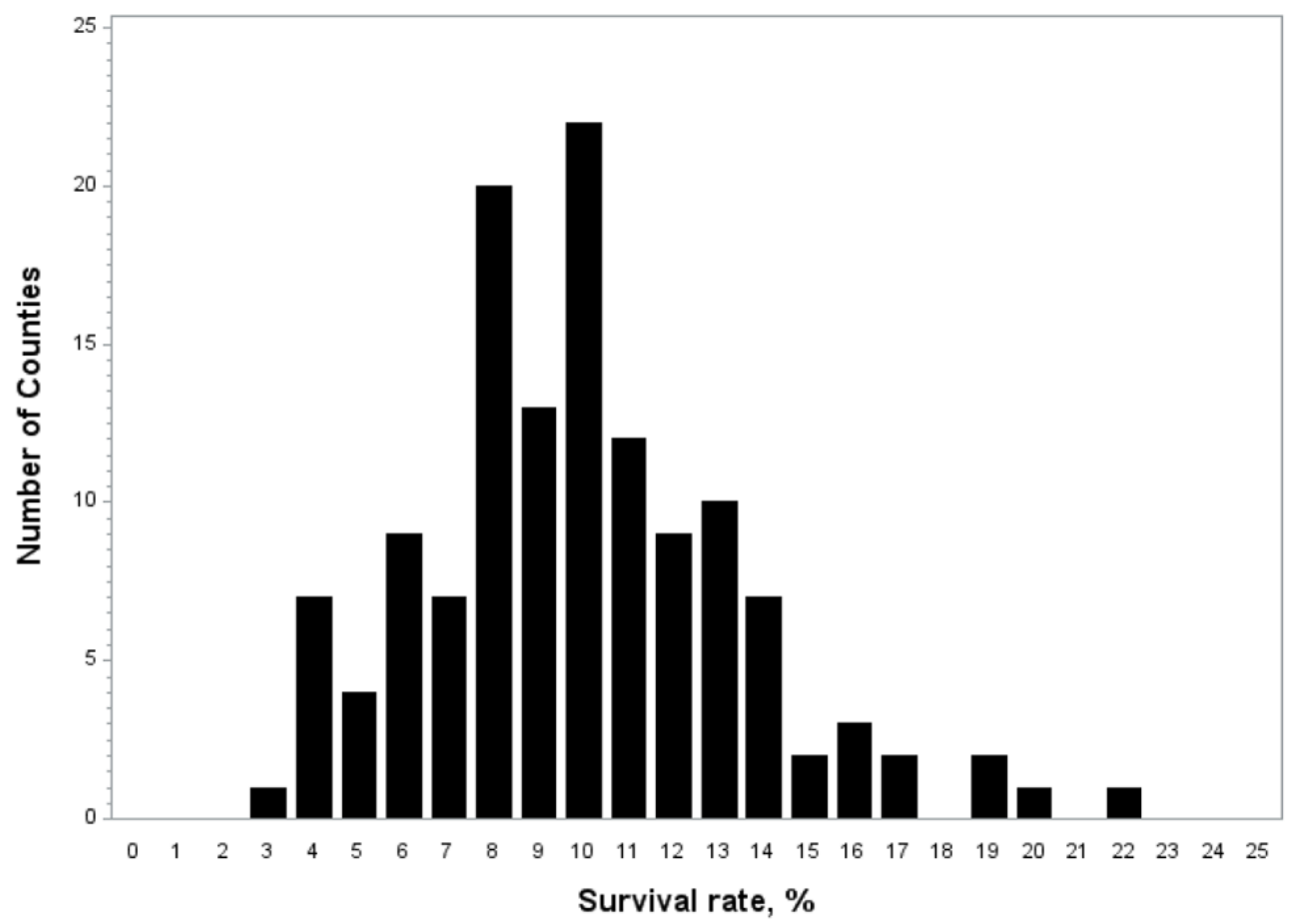

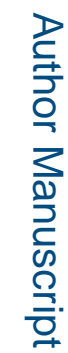

Figure 2a 


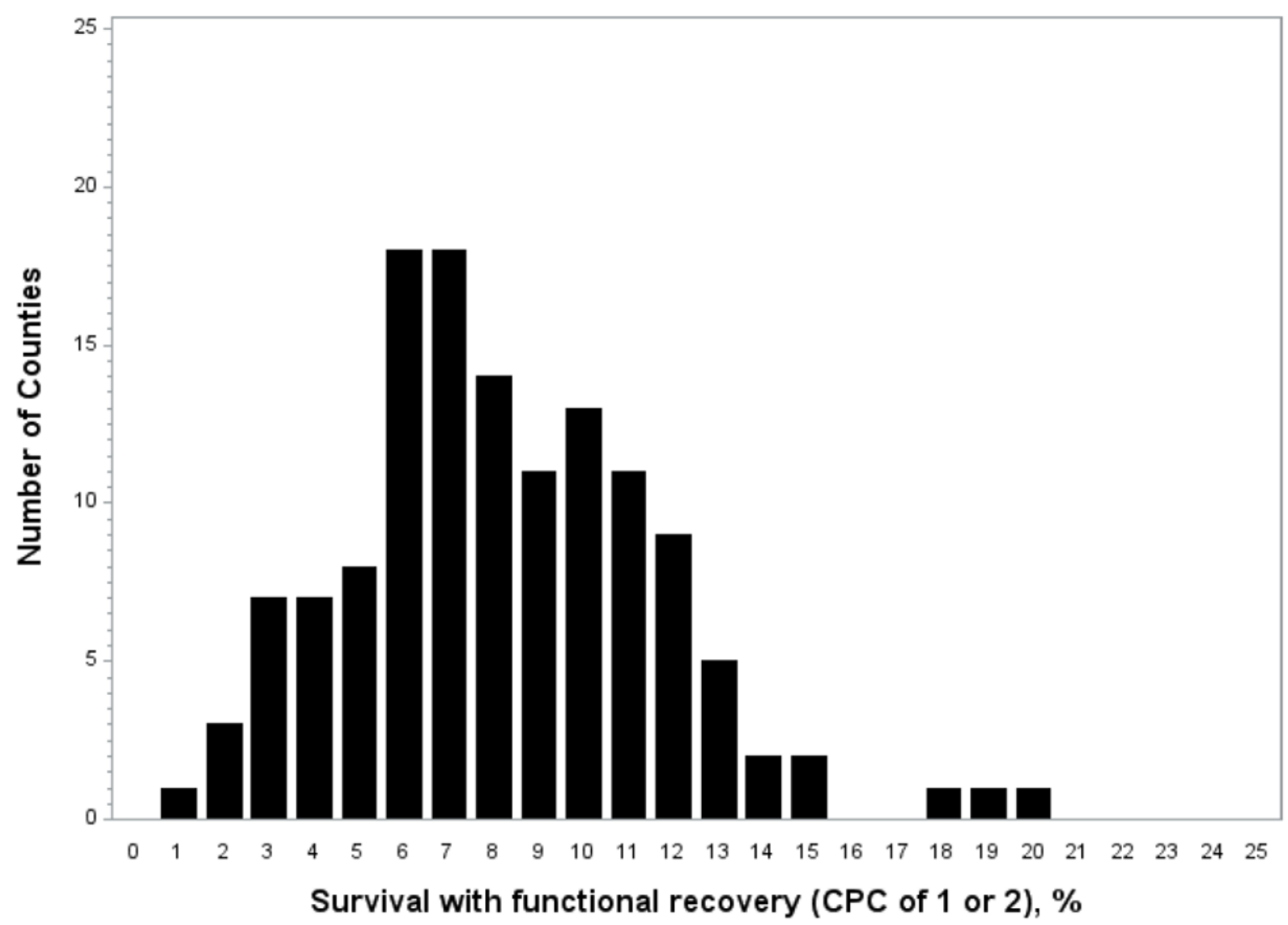

Figure 2b

Figure 2.

Variation in county-level rates of A) survival to discharge and B) survival with functional recovery. 


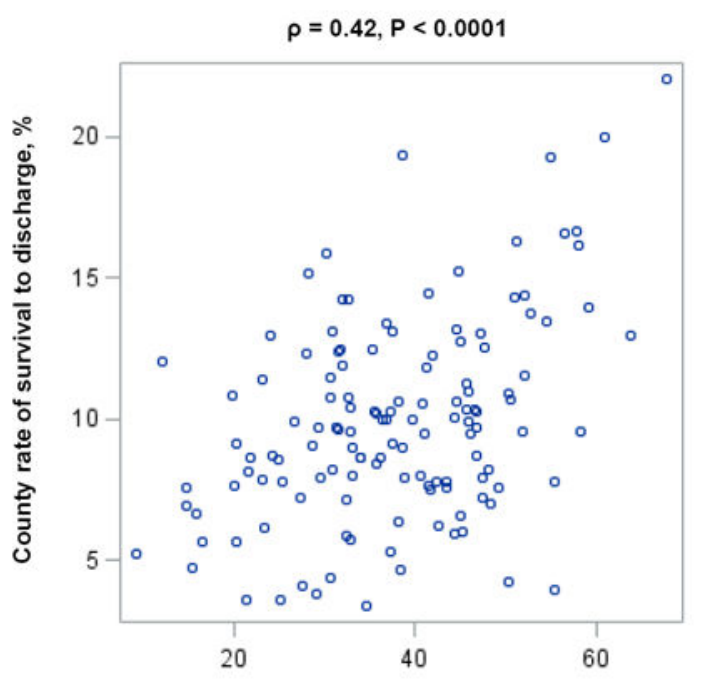

County rate of bystander CPR, \%

\section{Figure 3a}

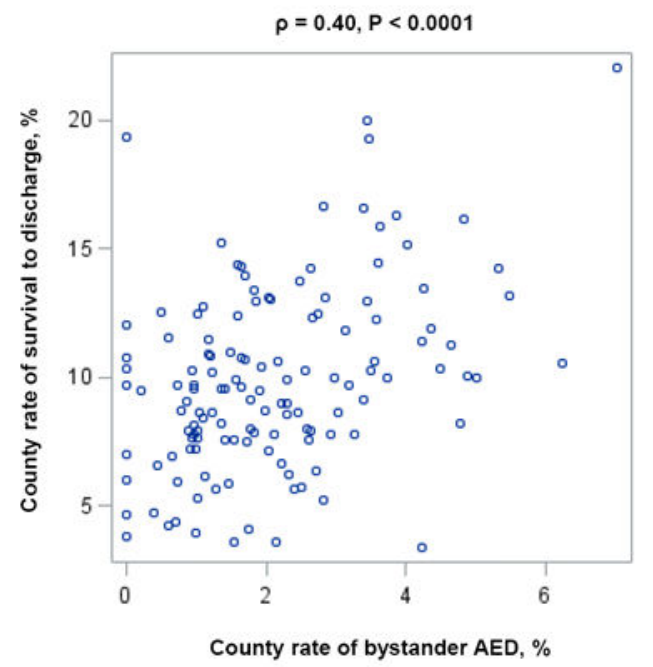

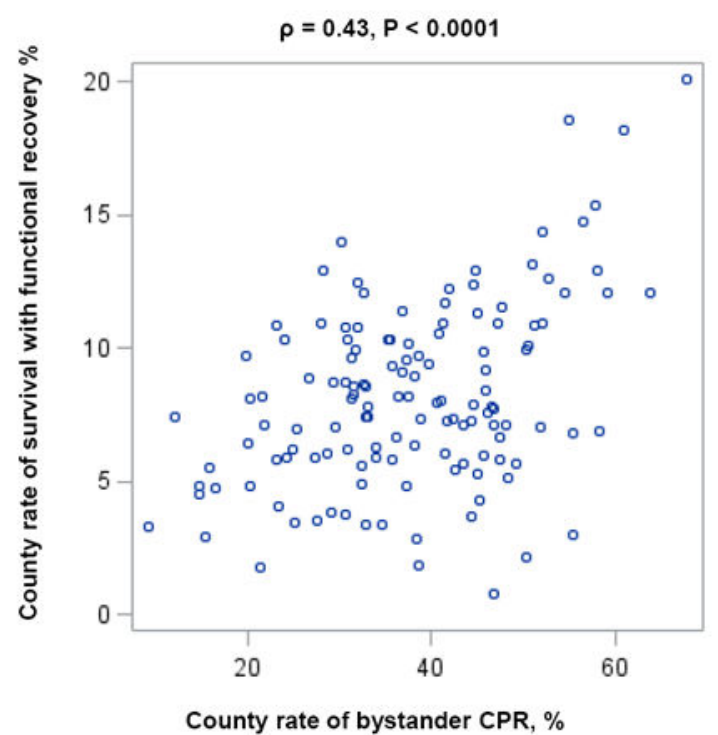

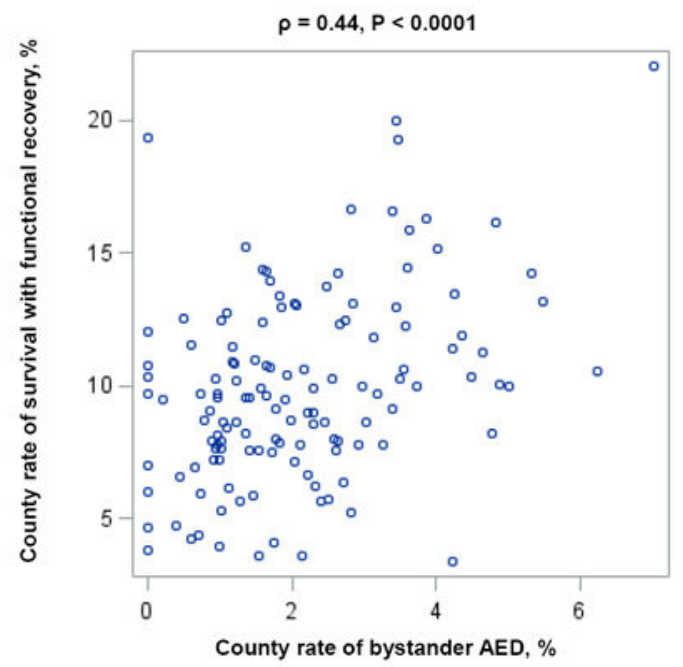

Figure 3b

Figure 3.

Correlation between county-level rates of survival outcomes and A) rates of bystander CPR, and $\mathbf{B})$ rates of bystander AED. 


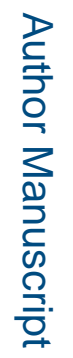

\begin{tabular}{|c|c|c|c|c|c|c|c|c|c|c|c|c|c|c|c|c|c|c|c|c|c|c|c|c|c|}
\hline 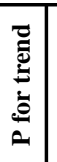 & & bे & $\frac{n}{0}$ & & & & & $\begin{array}{l}\overline{8} \\
\stackrel{8}{\circ} \\
\dot{\nabla}\end{array}$ & $\begin{array}{l}\overline{8} \\
\dot{0} \\
\dot{\nabla}\end{array}$ & & & & & 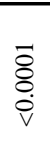 & $\begin{array}{l}\bar{\Xi} \\
\dot{0} \\
\dot{\nabla}\end{array}$ & & & $\begin{array}{l}\vec{\Xi} \\
\dot{0} \\
\dot{v}\end{array}$ & \begin{tabular}{|l}
$\overline{8}$ \\
$\dot{0}$ \\
$\dot{\nabla}$
\end{tabular} & $\begin{array}{l}\overline{8} \\
\dot{0} \\
\dot{\nabla}\end{array}$ & $\mid \begin{array}{l}\bar{\Xi} \\
\dot{0} \\
\dot{\nabla}\end{array}$ & & & & $\mid \begin{array}{l}\vec{\delta} \\
\dot{\nabla} \\
\dot{\nabla}\end{array}$ \\
\hline 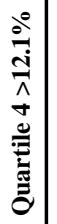 & 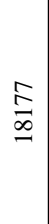 & $\begin{array}{l}\hat{\sigma} \\
\hat{n} \\
0 \\
\dot{f} \\
\dot{b}\end{array}$ & & $\begin{array}{l}\widehat{a} \\
\stackrel{d}{d} \\
\frac{\vec{a}}{\bar{a}}\end{array}$ & $\begin{array}{l}\hat{\infty} \\
\tilde{d} \\
\stackrel{d}{c}\end{array}$ & $\begin{array}{l}\stackrel{f}{\vec{d}} \\
\stackrel{d}{d} \\
\infty \\
\infty \\
\infty\end{array}$ & 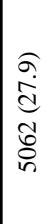 & 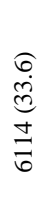 & & 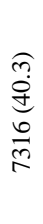 & 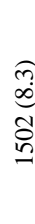 & 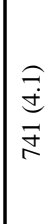 & 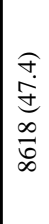 & $\begin{array}{l}0 \\
0 \\
0 \\
0 \\
0 \\
n \\
n\end{array}$ & & 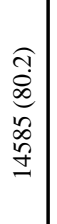 & 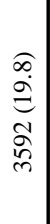 & $\begin{array}{l}\widehat{\infty} \\
\underset{\infty}{+\infty} \\
\stackrel{\hat{\infty}}{\infty}\end{array}$ & 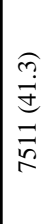 & $\begin{array}{l}\hat{\mathfrak{d}} \\
\underset{\infty}{\infty} \\
\stackrel{\infty}{o}\end{array}$ & & $\begin{array}{l}\widehat{ٍ} \\
\stackrel{\vec{c}}{\vec{c}}\end{array}$ & $\begin{array}{l}\hat{0} \\
\stackrel{0}{0} \\
\infty \\
\vdots \\
\vdots\end{array}$ & 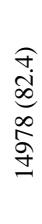 & 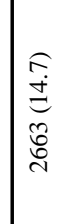 \\
\hline
\end{tabular}
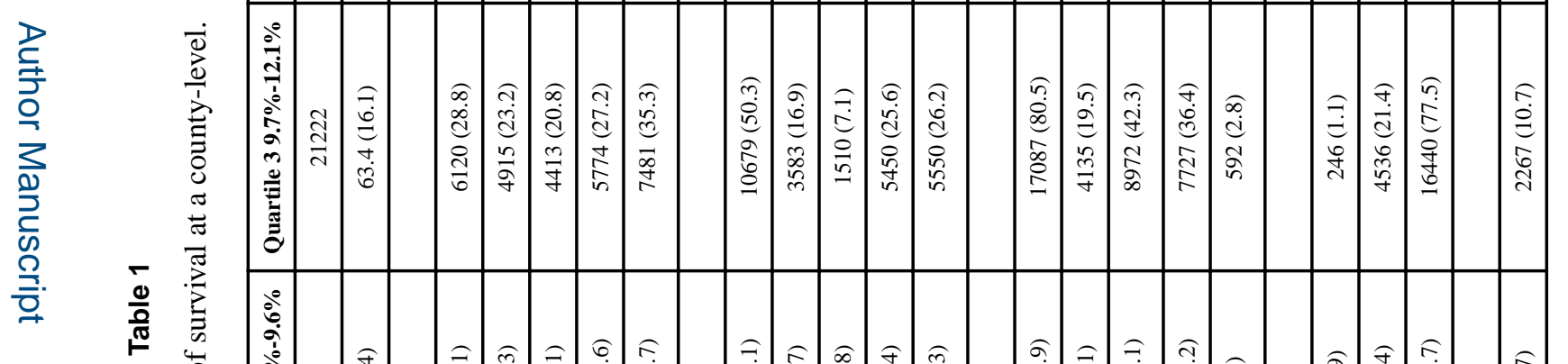

@
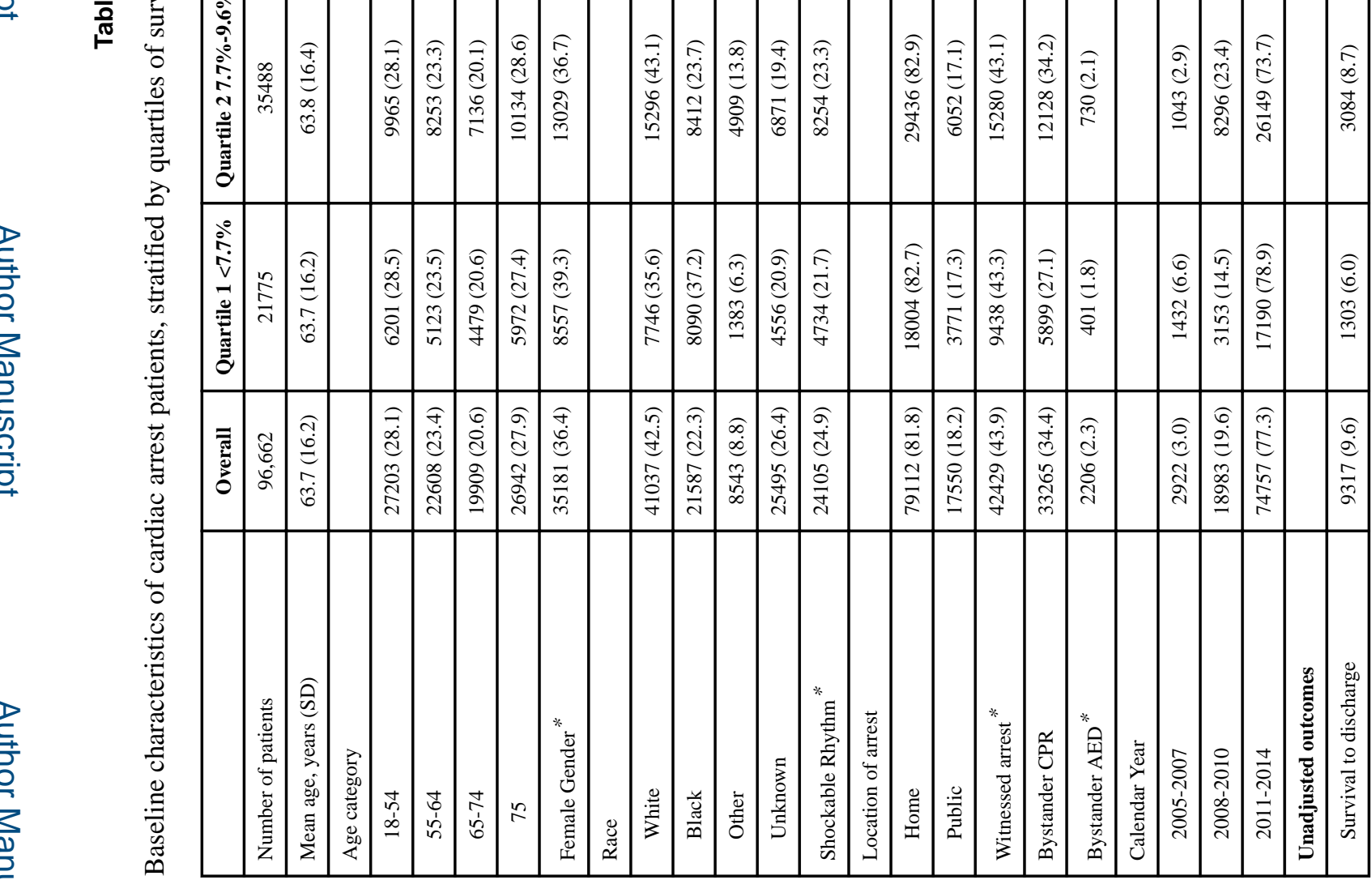

Circulation. Author manuscript; available in PMC 2017 May 31 


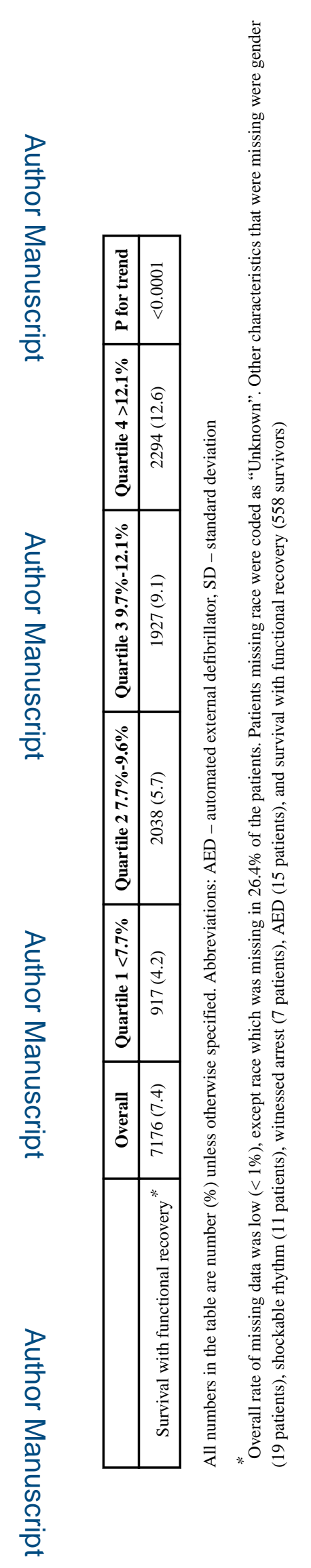




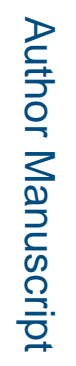

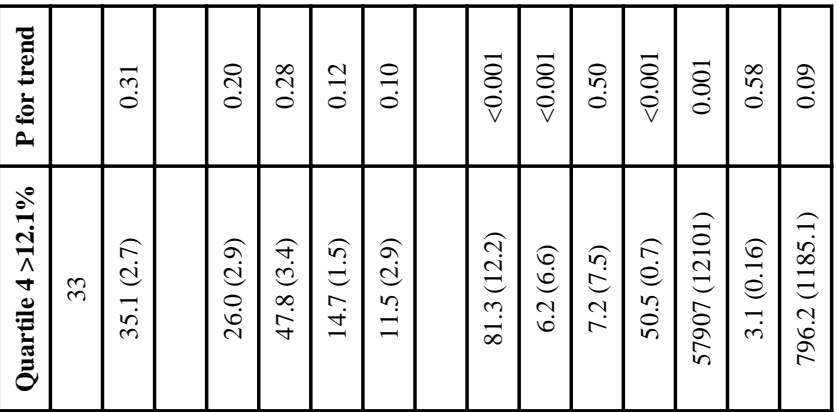

齐

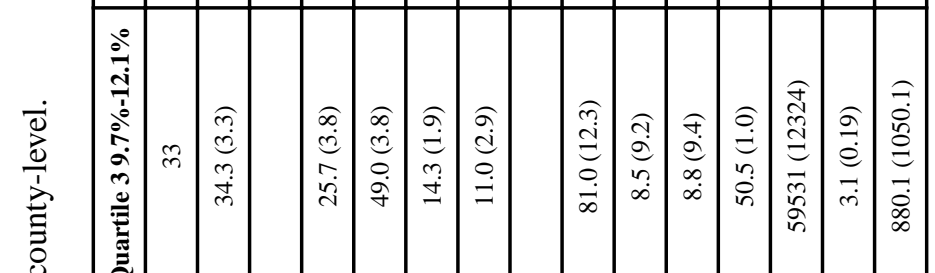

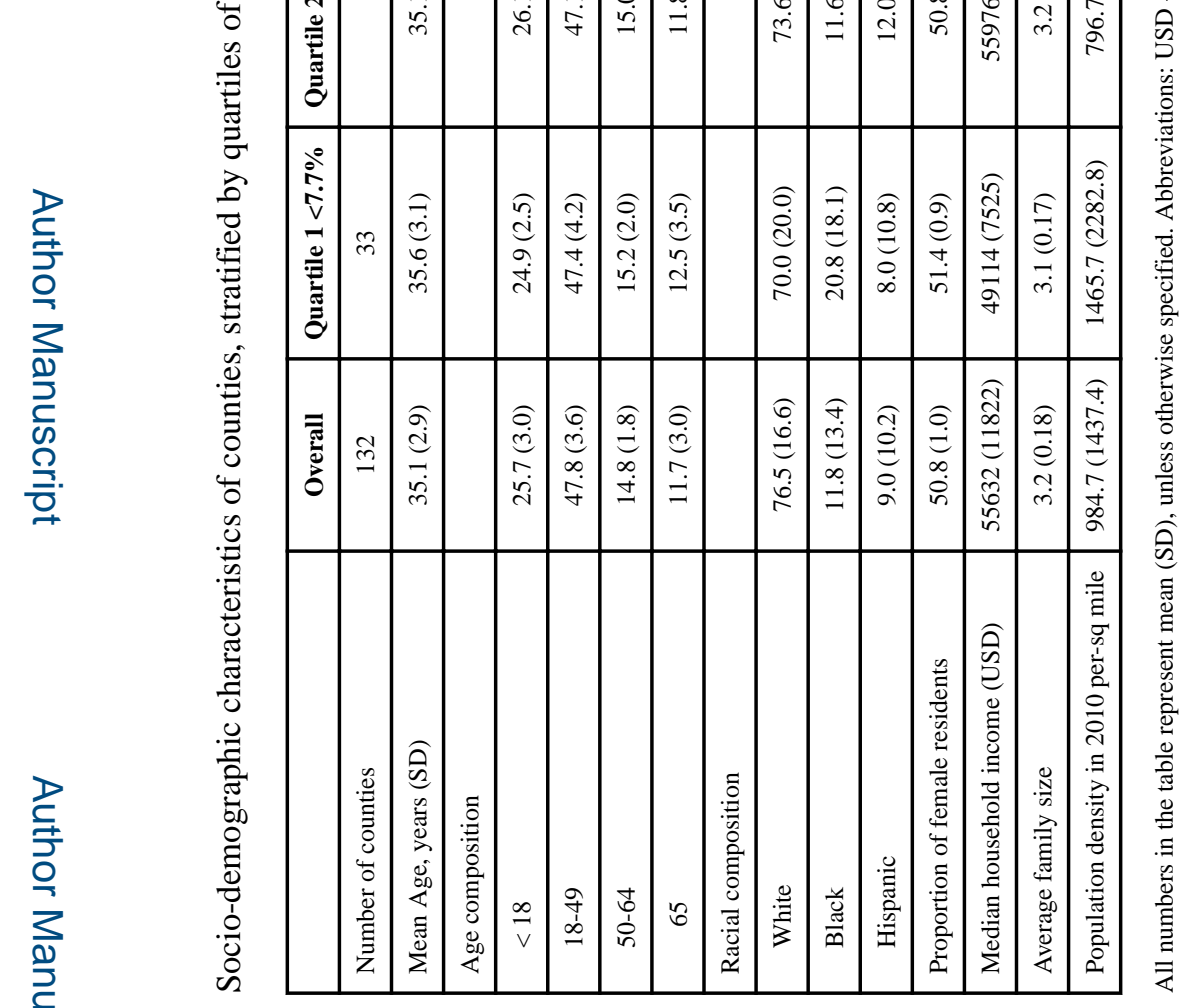

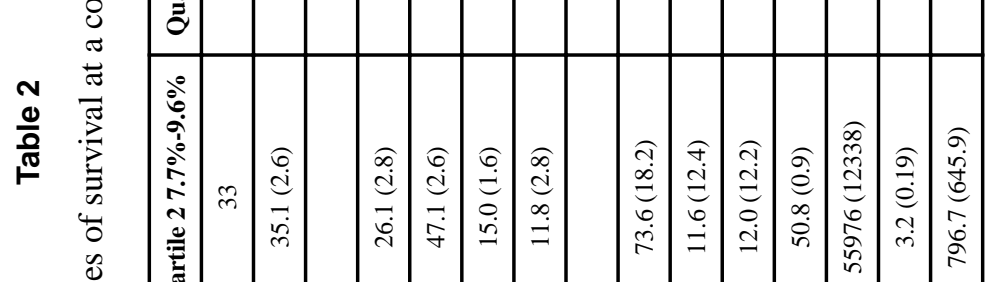

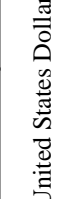

Circulation. Author manuscript; available in PMC 2017 May 31. 


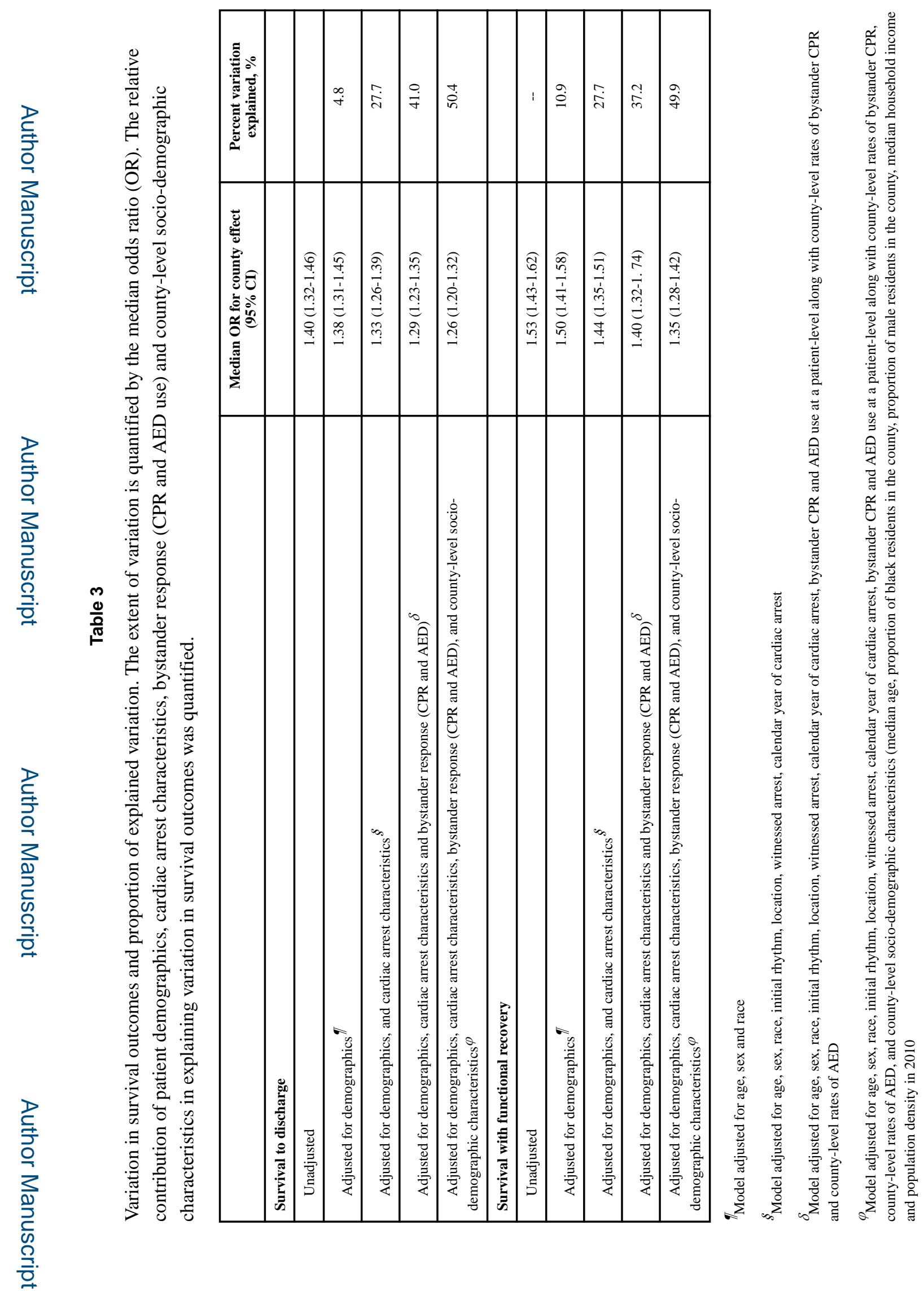

Circulation. Author manuscript; available in PMC 2017 May 31. 